OPEN ACCESS

Edited by:

Anders Hansen,

University of Leicester,

United Kingdom

Reviewed by:

Ulisses Miranda Azeiteiro,

University of Aveiro, Portugal

Sibo Chen,

Ryerson University, Canada

*Correspondence:

Anna Scaini

anna.scaini@natgeo.su.se

tORCID:

Anna Scain

0000-0002-3527-0241

Chiara Scaini

0000-0001-9645-7918

Jay Frentress

0000-0003-3897-660X

Georgia Destouni

0000-0001-9408-4425

Stefano Manzoni

0000-0002-5960-5712

Specialty section:

This article was submitted to

Science and Environmental

Communication,

a section of the journal

Frontiers in Environmental Science

Received: 20 April 2020

Accepted: 11 January 2021

Published: 19 February 2021

Citation:

Scaini A, Scaini C, Frentress J, Destouni $G$ and Manzoni S (2021)

Linking the 2030 Agenda for Sustainable Development to Research, Newspapers, and Governance: The

Case of the Last Free-Flowing Alpine River.

Front. Environ. Sci. 9:553822. doi: $10.3389 /$ fenvs.2021.553822

\section{Linking the 2030 Agenda for Sustainable Development to Research, Newspapers, and Governance: The Case of the Last Free-Flowing Alpine River}

\author{
Anna Scaini ${ }^{1,2 * t}$, Chiara Scaini ${ }^{3 \dagger}$, Jay Frentress ${ }^{4 \dagger}$, Georgia Destouni ${ }^{1,2 \dagger}$ and \\ Stefano Manzoni ${ }^{1,2 t}$ \\ ${ }^{1}$ Department of Physical Geography, Stockholm University, Stockholm, Sweden, ${ }^{2}$ Bolin Centre for Climate Research, Stockholm \\ University, Stockholm, Sweden, ${ }^{3}$ National Institute of Oceanography and Applied Geophysics - OGS, Italy, ${ }^{4}$ Ramboll Sweden, \\ Stockholm, Sweden
}

Are academic, newspaper and regulatory documents aligned with the United Nations Sustainable Development Goals and the Sendai Framework for Disaster Risk Reduction (SENDAI)? To answer this question, we develop a framework to compare the most commonly occurring keywords across these document types, as well as their use of Sustainable Development Goals and SENDAl keywords. The approach is tested in a case study on the Tagliamento River in the Italian Alps to explore the degree of communication among academia, newspapers and governance. Across the analyzed documents, we found disconnection between academic sources and regulatory documents. Occurrences of SDG-related keywords are positively correlated in regulatory documents and newspapers $(r=0.6)$, and in academic literature and newspapers $(r=0.38)$, indicating some degree of agreement. However, no correlation emerges between academic and regulatory documents, indicating a critical gap for communication and understanding between academic research and governance.

Keywords: Sustainable Development Goals, SENDAl, scraping, word occurrence analysis, Tagliamento River

\section{INTRODUCTION}

The United Nations (UN) 2030 Agenda for Sustainable Development includes 17 Sustainable Development Goals (SDGs), which prioritize global challenges for sustainability, including climate change, poverty, inequality, environmental degradation, and threats to water security and safety (Fukuda-Parr, 2016). Other frameworks have been developed to address sustainability challenges, such as risk management in the face of increasingly frequent extreme events (IPCC, 2012). To this aim, endorsed by the UN General Assembly following the 2015 Third UN World Conference on Disaster Risk Reduction (WCDRR), the Sendai Framework for Disaster Risk Reduction (SENDAI) has been proposed. The expected outcome of SENDAI is "the substantial reduction of disaster risk and losses in lives, livelihoods and health and in the economic, physical, social, cultural and environmental assets of persons, businesses, communities and countries".

Both SDG and SENDAI frameworks consider water a central resource, an ecological habitat, and/ or a risk factor. Globally, water-related disasters affect 160 million people annually, causing the 
deaths of approximately 13,500 annually (Ligtvoet, 2018) while extreme weather has led to more than 450 billion EUR in losses between 1980 and 2017 (European Environment Agency, 2019). Links between sustainable development and various waterrelated issues can be identified for all 17 SDGs. Water-related targets are specified in at least five SDGs (Engström et al., 2019; Jaramillo et al., 2019), with complex relationships, synergies, and trade-offs among them (as presented in Le Blanc, 2015). Among freshwater bodies, rivers are greatly affected by human activities and also represents a frequent source of damage (e.g., by flooding). As such, sustainable use of and risks associated with rivers are a focus for implementation of the guidelines proposed in both frameworks. River and river basin management are relevant to multiple SDGs, including health, clean water and sanitation, energy, infrastructure, life on land and below water, climate action and sustainable cities (SDG-2, 6, 11, 14, 15). River management for sustainable development encompasses both water quantity and quality, including their associated effects on ecosystems.

Human interventions to manage water quantity are mostly related to river fragmentation, flow regulation, sediment trapping, water consumption, and infrastructure development in riparian areas and floodplains (Grill et al., 2019). Such interventions affect free-flowing rivers and the ecosystem processes, biodiversity and services that these rivers support (Grill et al., 2019). Not only do such human disturbances reduce river-related biodiversity (Albert et al., 2020) and ecosystem services (Elmhagen et al., 2015), but they also increase hydrologic risks, such as the frequency of occurrence of both droughts and floods (Destouni and Verrot, 2014), and the likelihood of flood damages to agricultural, residential and industrial infrastructure (Di Baldassarre et al., 2013). Therefore, human interventions often lead to unsustainable changes in hydrologic regimes and associated ecosystem services.

Anthropogenic water quality deterioration relates directly to multiple SDGs, in particular SDG-2 on health, SDG-6 on clean water and sanitation, SDG-15 on life on land, SDG-14 on life below water, and SDG-11 on sustainable cities. Industry and agriculture can negatively affect various aspects of water quality, due to toxicity of pollutants, pharmaceuticals and microplastics (Borrely et al., 2018; Ma et al., 2019; Santos and Nardocci, 2019). They also alter water composition and conditions; e.g., in terms of temperature, salinity, electrical conductivity, concentrations of nutrients and other substances, and their impacts on eutrophication (Bouwman et al., 2009; Howarth et al., 2012; Bowles et al., 2018) and ecosystem status (Destouni et al., 2017). Most of the water quality threats are invisible, but have a strong impact on society (Damania et al., 2019). Both The EU Water Framework Directive (WFD) (European Council, 2000) and the EU Groundwater Directive (European Commission, 2008) are in place to address anthropogenic water pollution and its ecological implications, suggesting that these problems and their impacts on sustainability of water resources are well understood and deeply integrated in legislation.

While anthropogenic impacts on rivers and risks posed by rivers to society may be known, different actors understand and communicate these concerns in contrasting ways. Community engagement is mainly reflected by traditional media, such as television and newspapers, and internet sources. The perspectives of this media may differ from those of scientific research and how they are communicated with and perceived by the general public (Patenaude, 2011). Quantifying the relations and possible disconnections of issues perceived as important in research and by society is a challenge, as it requires linking different types of information. Scientific evidence is typically published in peer-reviewed journals using a well-defined set of technical terms, which can be analyzed by bibliometric mapping to assess their cooccurrence, i.e., the frequency of occurrence of these terms in the research articles (Batista et al., 2019), the main topics covered, and their relationships (Mora-Valentín et al., 2018). In contrast, mass-media, including online newspapers, spread information to the general public and allow a more rapid communication of ideas and concerns, but are heterogeneous in their terminology and structure. In the past, analyses of newspaper coverage has been used to provide insights on public opinion (Woodward, 1934; Kennamer, 1992; Riffe et al., 2019) and in relation to governance (Feldpausch-Parker et al., 2013; Tang and Rundblad, 2017). In particular, Hale (2010) analyzed newspaper coverage to assess the societal awareness and acceptance of ecosystem management models, using the case study of two river-floodplain nature reserves in the U.S. and in Central Europe. Their analysis underlined the importance of balancing human and ecological needs as well as the benefits of involving stakeholders in the river management process alongside education and outreach activities. However, examples of combined academic and non-academic analysis, that could underline the differences between the two, are lacking.

Given the importance of the SDG and SENDAI frameworks, it is surprising that there are no examples, to our knowledge, of combined analysis of academic and non-academic literature on these objectives and targets. Across the academic sector, leading social science and management journals have tackled the topic of sustainable development extensively, but research on the 2030 Agenda is less developed (Goodall, 2008; Patenaude, 2011; Carabine, 2015). In addition, the prioritization of certain targets may also influence the implementation of the 2030 Agenda (Oliveira and Almeida, 2019), highlighting a need to properly analyze various SDG targets (Nilsson et al., 2016; Nilsson et al., 2018) and how represented they are. We therefore propose a methodology based on previous work on social media trends to explore the presence of SDG and SENDAI topics in three different sources of information: academic literature, newspapers, and regulatory documents, further focusing on a river management case study.

We hypothesize that:

1. SDG and SENDAI topics are covered differently by the different sources of information. Thus, we hypothesize a disconnection between the way topics are covered by academic and public sources.

2. The coverage of SDG and SENDAI topics in local regulatory documents is intermediate between the academic literature and newspapers, potentially representing a bridge between scientific knowledge and societal needs. Hence, the SDG and SENDAI topics in local regulatory documents is 
expected to be partially correlated with both academic literature and newspaper.

To test these hypotheses, we select specific keywords for SDG and SENDAI objectives relevant for river management, and quantify their occurrence in academic literature, local newspapers, and regulatory documents. The prevalence of topic-specific keywords is then compared across the different sources that target overlapping and potentially distinct audiences.

We apply the proposed methodology to the Tagliamento River, considered as the last morphologically intact river in the Alps (Muller, 1995; Ward et al., 1999) and a reference ecosystem for large temperate river basins (Tockner et al., 2003). The river is widely used for human activities, such as hydropower production, industry (both water use and pollution), agriculture (both irrigation and pollution), extraction of gravel material, as well as tourism and recreation (Paronuzzi, 2005; Bacini Idrografici delle Alpi Orientali, 2009). Since 2004, large parts of the river are protected within the framework of the Natura 2000 sites of the Habitat 92/42/CEE directive (Brusarosco et al., 2010). The Tagliamento River attracts the interest of international academic groups, local and national policymakers, as well as the local community, and is thus appropriate to test how information on the river and its management is channeled across the media. Both security and safety aspects and the preservation of the river have received broad coverage in the local and the academic communities. Over the years, a number of political proposals and independent studies have been made to reduce flood risk to local communities, in particular to the floodprone city of Latisana. Plans to construct water retention basins to decrease peak flow, have been proposed and opposed multiple times (Toniutti and Ludovici, 2002; Toniutti, 2003; Toniutti, 2004). These contentious water management issues make the Tagliamento River a perfect case study to assess consistencies and differences across information sources.

The directions pursued in academic research and the extent of their impact on river management, status, and relationship with human activities (such as flood risk and its mitigation, damage to infrastructure, water quality and pollution) have not yet been analyzed. In addition, no previous studies have compared how academic literature, regulatory documents, and local newspapers portray and discuss river management and risk issues. With the proposed framework to compare coverage across document types, we identify current issues for the Tagliamento River, and suggest new strategies to increase cooperation between sectors of academia, media and governance.

\section{METHODS}

\section{Approach Overview}

In this work we use two types of keywords, which refer to (i) the most frequent words across information sources (academic, newspaper and regulatory document keywords), and (ii) the words selected from the UN objectives (UN keywords). Here we use the term "UN objectives" as comprising both (i) the Sustainable Development Goals (SDG) and their relevant targets, and (ii) the SENDAI framework, with seven targets and four priorities for action. Furthermore, the SDG and SENDAI framework are structured in different ways and employ specific terms (goals, priorities, and targets); here we use the term "target" as a general term, referring to both targets and priorities within the UN objectives.

With the term "occurrence analysis" we refer to the quantification of occurrences of keywords across academic, newspaper and local regulatory sources. We define "general word occurrence analysis" as the analysis of the most frequently occurring words within each information source. The "UN occurrence analysis" is the analysis of the occurrence of UN keywords within each information source. The methodology consists of three main steps (Figure 1):

(1) Identification of information sources: academic literature, newspaper and local regulatory documents.

(2) Selection of content and keyword groups:

a) Keywords in academic literature, newspaper and local regulatory documents, identified by screening the documents and retrieving the most frequently occurring words.

b) UN keywords, identified by sieving through the SDG and SENDAI frameworks, analyzing specific targets under each goal and selecting those that are relevant to the purpose of this analysis.

(3) Occurrence analyses:

a) General word occurrence analysis (based on 2-a): analysis of the occurrence of (i) academic keywords, (ii) newspaper keywords and (iii) local regulatory document keywords.

b) UN occurrence analysis (based on 2-b): analysis of the occurrence of UN keywords in the three information sources (newspaper, academic and regulatory documents).

\section{Data Retrieval and Filtering Academic Literature}

A literature search in the Web of Science (WOS) database was conducted on the sixth of December 2019, to gather articles that reported studies on the Tagliamento River basin. The following string was searched in WOS Core Collection: "TOPIC: (Tagliamento River); timespan: all years; indexes: SCIEXPANDED, SSCI, A\&HCI, CPCI-S, CPCI-SSH, ESCI”. The query returned 270 research articles, with publication dates between 1993 and 2019. These articles were then sifted through a systematic title and abstract screening to exclude articles that were not mainly related to the Tagliamento River but initially retained by the automatic filter. Titles, abstracts, keywords and bibliographic information from the returned 238 articles were exported to a text file. Two types of keywords were included in the analysis: author-defined and automatically retrieved. The automatically retrieved keywords were extracted with a "Walk-on-Spheres" text analysis algorithm, which is based on the continuous random walk method (first introduced by Muller, 1956). The specific method used within the WOS database is called Keyword Plus ${ }^{\circledR}$ (Garfield and Sher, 1993). 


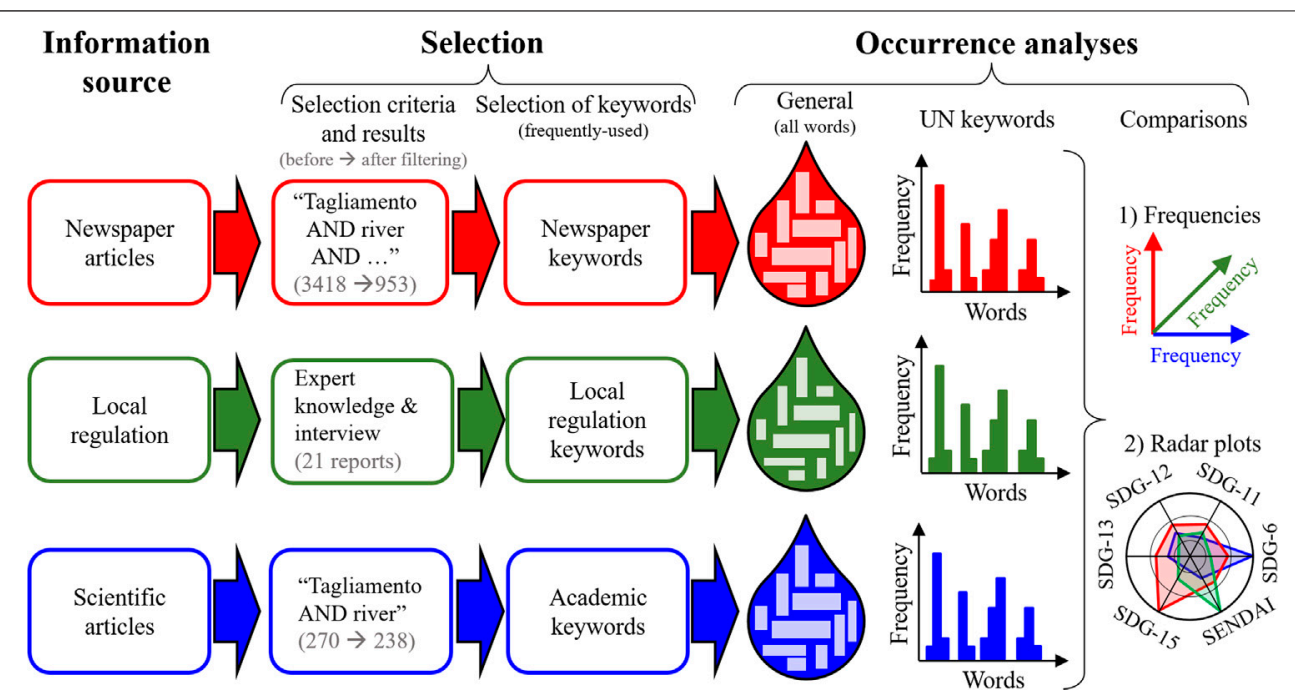

FIGURE 1 | Schematic showing the information sources, selection criteria, and occurrence analyses leading to comparisons of word occurrences across the three information sources.

When available, the fields "grant number" and "funding agency" were also retained for each research article. All academic literature was in English.

\section{Local and National Newspapers}

Local newspapers have hosted most of the general public debate on the Tagliamento River. Thus, we regarded them as representative of the perspective and perception of people living in the Tagliamento River basin. According to Audipress (2017), the most read newspapers in Friuli Venezia Giulia are Messaggero Veneto, Il Piccolo and Il Gazzettino. Additional local newspapers were identified from the available online sources. For completion, the top-two national newspapers ( La Repubblica, Corriere della sera) and the first multimedia information agency in Italy (Ansa) were also screened.

The newspaper article selection was based on the number of results found by searching the word Tagliamento in each journal search engine. Specifically, we searched the occurrences of the word Tagliamento in at least one of the following fields: title, subtitle or body. Ansa provided very few results (less than 100 in the whole time period) and was therefore not retained in the analysis. Other newspapers did not provide a robust search page, so that the articles could not be retrieved. In particular, Il Gazzettino was not retained in the analysis due to the impossibility of downloading articles older than 15 days. After the search, a total of four local newspapers (Messaggero Veneto, $\mathrm{Il}$ Piccolo, Il Friuli, Udine Today) and two national newspapers ( $L a$ Repubblica, Corriere della sera) were selected from the initial, broader pool.

Articles were then retrieved from each newspaper's website by scraping the $h \mathrm{tml}$ (i.e., extracting information from a website source) with a Python script. The script also automatically filtered the search results, and downloaded only articles that satisfied two conditions: a) occurrence of the word "Tagliamento" in at least one of three inspected fields (i.e., title, subtitle or body) and b) occurrence of one of the following words in the article body or title (searched for in Italian: fiume, acqua, corso d'acqua, sponda, riva, greto; in English: river, water, watercourse, river bank, river bed, stream). All words were searched in singular, plural and their most commonly conjugated forms. The second condition was added in order to speed up the process of automatically downloading thousands of articles and in order to pre-filter results to make sure that they dealt with the Tagliamento River. The chosen terms were intentionally general and not specifically related to scientific aspects. The extracted articles were later sifted through a systematic manual screening to exclude residual unrelated articles (i.e., dealing with some events happening at the Tagliamento River but not concerning the river itself, or referring to a town that contains Tagliamento in its name).

Table 1 shows the number of search results in the newspaper websites, and the number of articles after automatic and manual filtering. After filtering, a total of 953 newspaper articles were retained for further analysis. The majority of the newspaper articles come from Il Messaggero newspaper. The newspaper for which we discarded the smallest fraction of entries is $\mathrm{Il}$ Friuli. Overall, the percentage of discarded articles was high (Table 1).

\section{Local Regulatory Documents}

In addition, a search was conducted to identify relevant local regulatory and institutional documents. We selected the main official documents issued from the Friuli Venezia Giulia region, where most of the catchment is located, regarding the Tagliamento River and the general river basin management. We did not include technical and nontechnical reports written specifically for the Tagliamento River by third parties and non-governmental organizations (e.g., WWF). The total number of documents was 21 (See SI for the complete list). 
TABLE 1 | Newspaper search results at the time of the analysis (December 06, 2019), including the newspaper name, period of time available for download, total number of articles downloaded, number of articles retained for the analysis after filtering, and percentage of articles retained for the analysis (i.e., percentage of articles retained out of the total number of articles). The total as sum of the articles downloaded and retained for all the newspapers is also shown.

\begin{tabular}{|c|c|c|c|c|}
\hline Newspaper & Period available & $\begin{array}{c}\text { Total number of } \\
\text { articles downloaded }\end{array}$ & $\begin{array}{l}\text { Number of articles } \\
\text { retained for the } \\
\text { analysis }\end{array}$ & $\begin{array}{c}\text { Percentage of retained } \\
\text { articles }\end{array}$ \\
\hline Messaggero & 2003-2019 & 22,565 & 710 & $3 \%$ \\
\hline // Piccolo & 2003-2019 & 9,758 & 105 & $1 \%$ \\
\hline La Repubblica & 2001-2019 & 1,060 & 17 & $2 \%$ \\
\hline UdineToday & 2011-2019 & 834 & 52 & $6 \%$ \\
\hline Corriere della sera & 2001-2019 & 463 & 1 & $<1 \%$ \\
\hline // Friuli & 2006-2019 & 184 & 68 & $37 \%$ \\
\hline Total & & 34,864 & 953 & $3 \%$ \\
\hline
\end{tabular}

\section{Keyword Identification and Translation}

The most frequently used keywords from the three information sources were analyzed to address if and how academic, newspapers and local regulatory documents are correlated in content. To analyze the word occurrences (General Word Occurrence Analysis), frequently used keywords in the three information sources were searched:

- Academic keywords: keywords based on the academic literature identified through the methodology described in Academic literature.

- Newspaper keywords: keywords based on the newspapers identified through the methodology described in Local and national newspapers.

- Local regulatory keywords: keywords based on the reports identified through the methodology described in Local regulatory documents.

Additionally, UN keywords were identified and searched within the three information sources to explore how well these sources reflect the objectives of the 2030 UN agenda. Specific keywords were selected by the authors and their occurrence was searched in the three information sources:

- UN keywords: keywords based on the UN objectives, hereby defined as (i) the Sustainable Development Goals (SDG) and their relevant targets, and (ii) the SENDAI framework, with seven targets and four priorities for action.

The UN keywords were selected based on the official description of the SDG goals, sieving through the text of both the short overarching goal summary and the specific targets under each main goal. Similarly, the SENDAI framework was analyzed and additional UN keywords were selected. Due to the subjectivity of keyword choices, for this analysis, all co-authors independently identified the targets (used here as a general term that includes the SENDAI targets and priorities of action) that each considered most relevant among those of the SDG and SENDAI frameworks and suggested corresponding keywords. A total of 22 targets were selected by all authors and subsequently retained for the analysis. Additionally, 24 more targets were selected by at least one author. While the main analysis will focus on the 22 targets selected by all authors, we will also compare results with those obtained from targets chosen by at least one author.

The identified SDGs were: SDG-6 - Ensure availability and sustainable management of water and sanitation for all; SDG-11 Make cities and human settlements inclusive, safe, resilient and sustainable; SDG-12 - Ensure sustainable consumption and production patterns; SDG-13 - Take urgent action to combat climate change and its impacts; SDG-15 - Protect, restore and promote sustainable use of terrestrial ecosystems, sustainably manage forests, combat desertification, and halt and reverse land degradation and halt biodiversity loss. The list of all underlying SDG targets, the SENDAI targets (four of which were considered relevant), as well as the four priorities of action, and associated keywords selected by all authors are available in SI. Some of the chosen keywords are phrases containing multiple words to follow the exact phrasing of SDG and SENDAI targets. Exact phrasing from the official English and Italian documents were used (United Nations, 2015a; United Nations, 2015b). The Italian translation of the full text of the SENDAI framework was further validated through the Civil Protection Department website - Presidency of the Council of Ministers (available at http://www.protezionecivile.gov.it/mediacomunicazione/dossier/dettaglio/-/asset_publisher/default/content/ una-strategia-comune-per-la-riduzione-del-rischio-disastri).

\section{Keyword Occurrence Analysis}

For the analysis of newspapers and regulatory documents-all written in Italian-we could not use readily available software because it does not work with languages other than English. Thus, we wrote specific Python codes to perform the keyword occurrence analysis and used them consistently across all information sources.

\section{General Word Occurrence Analysis}

To perform the general word occurrence analysis, the most frequently occurring words in academic, newspaper and local regulatory sources were identified. For academic articles, the title and abstract were analyzed. For newspaper articles and regulatory documents, the title, subtitle and body were analyzed. In all cases, the analysis produced a list of all words and corresponding number of occurrences. The occurrences were converted into a 
'relevance' index by normalizing the absolute occurrence frequency to between 0 and 100 ( 0 = word with lowest number of occurrences; $100=$ word with highest number of occurrences). The words with a relevance greater than 0.1 in each information source were then retained and plotted as word clouds. Words with multiple meanings were omitted (i.e., the word state can be used as a verb or a noun, which can lead to over counting in ways that are not reflective of the topic). The word river has been omitted because it was part of the original search criteria. Academic keywords, newspaper keywords, and local regulatory keywords were compared across information sources. To perform the comparison, the keywords were translated from Italian to English when necessary. Word clouds were used as a simple means to show similarities or differences across the three information sources.

\section{UN Occurrence Analysis}

To explore how each of the information sources reflects the objectives of the 2030 UN agenda, we performed the UN occurrence analysis. In some instances, the UN keywords selected by all the authors from the Italian text of SDG and SENDAI resulted in a higher number of keywords than the English version, due to singular/plural forms. Such keywords were then combined in the English corresponding translation to reach the same result.

For each SDG and SENDAI target, we calculated the sum of the UN keyword occurrences (as identified in Local Regulatory Documents). The total occurrences for each target were then normalized by dividing the number of UN keyword occurrences by the total number of words in each information source. For newspaper and scientific articles, the total number of words was calculated only from the selected articles. This normalization was performed separately for each information source (academic, newspaper and local regulatory documents). This normalization allows comparing the UN keyword occurrences across the different UN targets for each information source. However, because some targets have more keywords than others, there will be more occurrences in targets with more keywords.

A second type of normalization was performed by dividing the UN keyword occurrences by the number of keywords in each target. Also in this case, the normalization was performed separately for each information source. This normalization allows comparing the UN keywords occurrences across the different UN targets without any bias caused by the different number of keywords for each target. However, in this case there will be more keywords in information sources with more total words. Therefore, the two normalization approaches provide complementary perspectives on how keywords are partitioned among information sources and targets.

\section{Correlation Analysis}

To test our hypotheses in a quantifiable way, Pearson's correlation coefficient was used to test if the same words were common in more than one information source, i.e., how similar information sources were in the word and frequency of words they used. The Pearson's correlation coefficient was calculated between the number of occurrences of common words from pairs of information sources. The Pearson's correlation coefficients were performed on log-transformed values. The correlation coefficient was not used in the general word occurrence analysis because of the limited word overlap (See General word occurrence).

\section{RESULTS}

\section{General Word Occurrence}

The most frequent words (with a relevance greater than 0.1 , see General word occurrence analysis) from academic, newspaper and local regulation sources are shown in word clouds respectively in Figures 2A-C. The number of words with relevance greater than 0.1 are 37 for academia, 61 for newspapers and 75 for regulation. The top-10 words for the three information sources are: Academic: channel, floodplain, flood, island, habitat, vegetation, sediment, flow, braided. Newspaper: water, Latisana, regional, river course, safety, mayor, Friuli, municipality, bridge, civil protection. Regulatory: plan, basin, water, areas, interventions, regional, habitat, landscape, protection, species. There is very little overlap among the most frequent words: only 4 words co-occur between academic and local regulation sources, 13 words between academic and newspaper sources, and 21 between newspaper and local regulation. The only words that co-occur in the three sources are area, flood and water. The word flood has an occurrence of respectively 0.26 in academic literature, 0.21 in newspapers articles and 0.24 in local regulatory documents.

\section{UN Keyword Occurrence}

A total of 147 UN keywords were identified for the 22 selected targets. The occurrence of these keywords in academic, newspaper and regulatory documents is shown in Figure 3. Based on our analysis, 55, 42, and 60 UN keywords occur at least once in these three sources, respectively. Most keywords occur in more than one of the sources, with a total of 62 different UN keywords occurring in at least one of the three source groups. These keywords are shown in Figure 3A. In the academic literature, the most-occurring $\mathrm{UN}$ keyword is environment, closely followed by ecosystem. Other frequently occurring UN keywords in the academic source are response, restoration, biodiversity, conservation, climate, aquifer, hazard and recovery. In newspapers, environment is also the most frequently occurring UN keyword, followed by risk, services and management of chemicals. In newspapers, these terms are followed by a number of terms that suggest actions, such as collaboration, protection, response, as well as access, climate and ecosystem. In the regulatory documents, risk is the mostoccurring UN keyword with almost 800 occurrences, followed by hazard and conservation. Environment is in the fourth place, despite a greater total number of occurrences in the regulatory documents than in both the academic and the newspaper literature. The other most-occurring UN keywords in regulatory documents are mitigation, services, infrastructure, protection, capacity and rehabilitation.

Figures 3B,C show results of the correlation analysis among word occurrences-correlated data indicate that words are on 

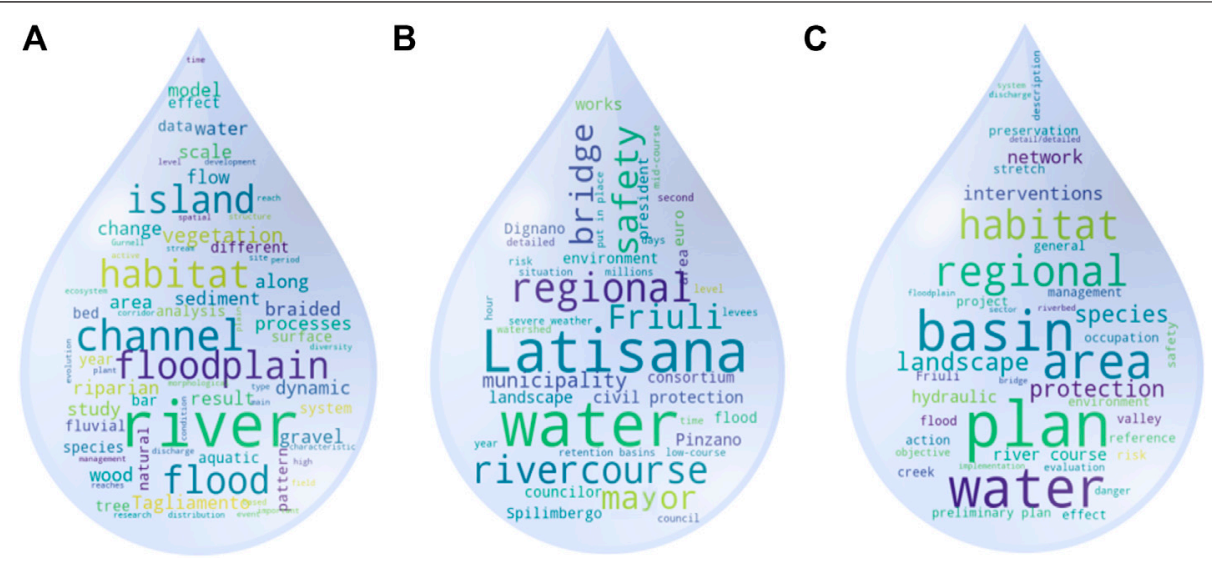

FIGURE 2 | Word clouds showing the most frequent words in the filtered academic literature (A), filtered newspapers articles (B), and local regulatory documents (C). All keywords are shown in English (translated).

average occurring with similar frequency in two sources; in contrast, un-correlated data indicate that words frequently appearing in one source do not appear in the others. Both plots show some level of agreement among sources, with significant ( $p$-value $<0.05$ ) Pearson correlation coefficients of 0.38 between academic literature and newspapers, and 0.6 between regulatory documents and newspapers. The Pearson's correlation coefficient between academic literature and regulatory documents is 0.17 (data not shown) and not significant ( $p$-value $=$ $0.16)$. Despite the general agreement between academic articles and newspapers seen in Figure 3B, some relevant keywords, like services, risk mitigation, risk management, infrastructure and pollution, have high relevance for newspapers, but are almost never used in the academic literature, drawing down the overall correlation. The correlation is higher between regulatory documents and newspapers, but also in this case some terms have high relevance for regulatory documents, but low occurrence in newspapers. Some of the terms occurring in regulatory documents, but not in newspapers, are rather technical terms, like restoration, adaptation, wastewater, while others are important for the general public, like public health.

Figure 4A shows the total UN keyword occurrences selected by all five authors, taken from the SDG and SENDAI frameworks. The UN keyword occurrences for each target are normalized by the total number of words within each of the three information sources (indicated by different colors) as described in 2.4.2. With this approach, we can compare the occurrences across the UN targets for each information source. The terms used in the SENDAI framework, related to disaster risk reduction and governance (in particular SENDAI-1), are highly represented in all sources. Specific SDG targets are also highly represented, but less consistently in the different information sources.

Because the number of occurrences increases with the number of keywords identified within each target (minimum $=2$, maximum $=22$ ), an additional normalization according to the number of keywords within each target was performed (Figure 4B). With this approach, we can compare the occurrences across targets, but the relative differences among information sources are caused by the contrasting total number of words in each source; e.g., regulatory documents are typically long, leading to a large number of keyword occurrences. In the academic literature, the main targets are SENDAI- 1 and -4, SDG15.1 and SDG-6.6. Newspapers also focus on terms included in most of the SENDAI targets, SDG-12.4 and 13.1. Finally, regulatory documents deal mostly with topics related to SENDAI targets, SDG-6.3, 11.B, 13.1, and 15.1. The two normalization approaches are consistent in identifying SENDAI-D, SENDAI- 1 to -4 , SDG-11 to -15 among the most frequently discussed targets across all information sources.

\section{DISCUSSION}

We have presented and applied a scalable framework to compare different types of information sources to each other via keywords associated with various UN sustainability objectives. The methodology allowed us to quantify the degree of consistency among information sources. In addition to those investigated here, the sources could include citizen-based information, which would widen the general applicability of the methodology. The presented methodology aims at facilitating assessment of the degree of information transfer from one source to another, by identifying consistencies in keyword occurrence across the different sources. In the following, we discuss the study results in the context of our hypotheses (Is There a Disconnection Between Science and Policy?) and in relation to the particular case of the Tagliamento River (Tagliamento River Management: $A$ Fragmented Debate?), as well as regarding more general implications of the methodology (Methodological Implications) and future outlook (Future Outlook).

\section{Is There a Disconnection Between Science and Policy?}

The disconnection across the information sources depends on which method is used to compare these sources-either general 


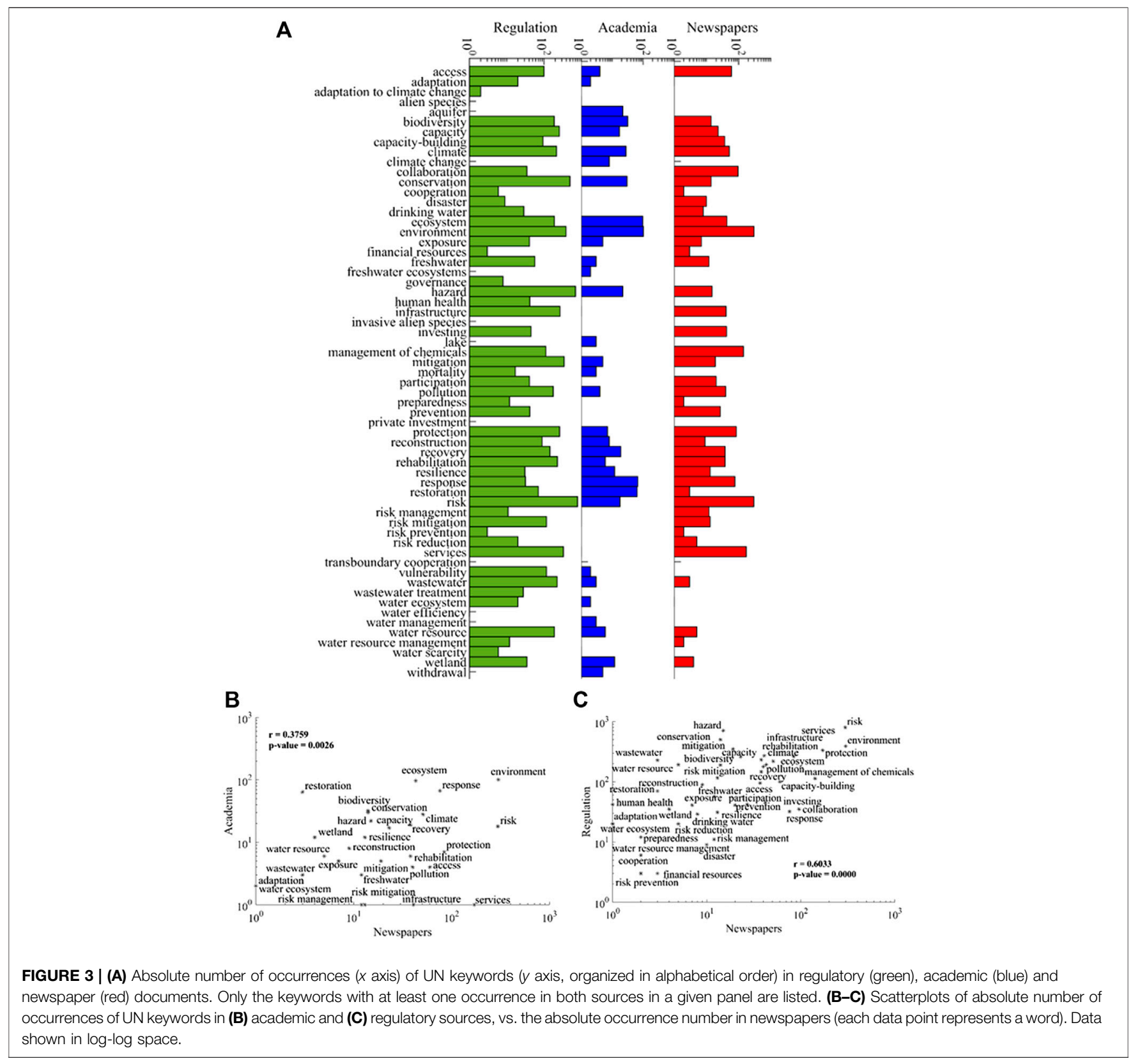

word or UN keyword occurrence analysis. The analysis of the most frequently occurring keyword in each of the three information sources, i.e., the general word occurrence analysis (General Word Occurrence), showed that the main topics covered within each source are indeed different from one another, at least in the context of the selected case study. Very few words co-occur in two of the information sources, and only four co-occur in the three sources, showing that overall the words used in each source are different. Academic literature focuses more on river dynamics, hydrological and morphological aspects, and less on river management and conservation issues. Regulatory documents focus more on river management, including allowable activities on the riverbed, ranging from bank protection and sediment management to organization of cultural events (related to hot topics identified in Methodological Implications). The local regulatory documents address common territorial planning topics, e.g., land management, construction of infrastructures, river banks maintenance and consolidation (relevant also for newspapers), as well as the problem of habitat protection (a topic in common with academic literature). Newspapers focus more on local politics and its relationship with the Tagliamento River, with the debate mostly driven by risk-increasing factors (e.g., autumn rain, summer activities, etc.).

While the general keywords hint to a lack of correlation among information sources, the UN keyword analysis showed correlations between occurrences of words used in academic literature and newspapers, and in regulatory documents and 


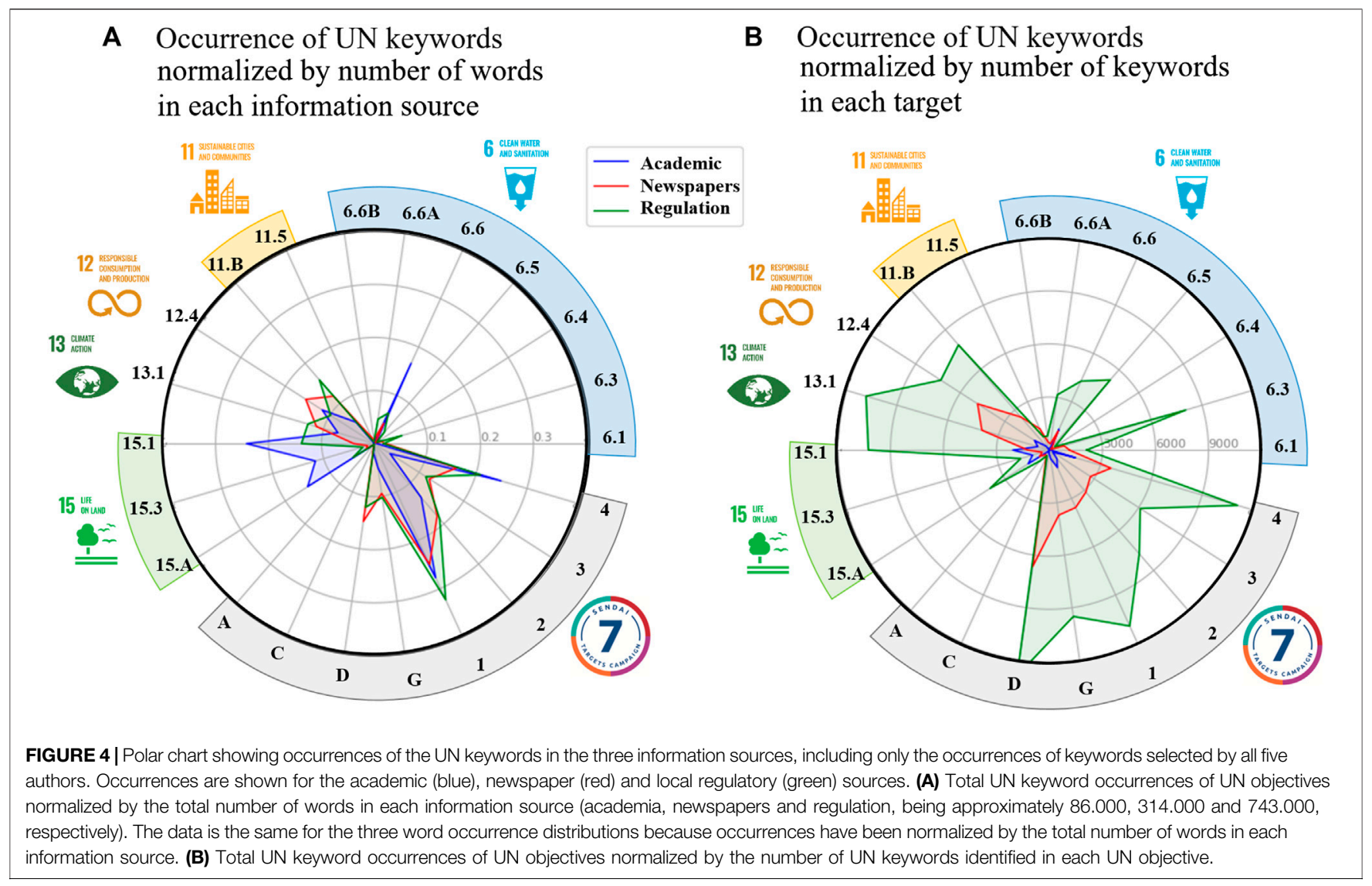

newspapers (Figure 3). In contrast, the UN keyword use in regulatory documents is not significantly correlated with that in the academic literature. The distribution of the UN keyword occurrences across SDGs and SENDAI objectives, however, showed strong differences between the three information sources, in particular for the SDGs (Figure 4). Academic literature focused on SDG-15 (biodiversity and ecosystem aspects) and SDG-6 (water access and management), specifically regarding target SDG-6.6 that regards protection and restoration of water-related ecosystems. In contrast, newspaper and regulatory documents focused more on SDG11, 12 and 13, which cover socio-economic aspects, environmental management and climate change, respectively. Overall, our analysis only partially supports our first hypothesis, where we expected to find differences in occurrence of SDG- and SENDAI-related topics across the academic, regulatory and newspaper sources, as we do find some discrepancies across the three information sources. In turn, some terms related to the SENDAI framework were often present in the three sources, in particular the SENDAI-1, focusing on disaster risk management (Figure 4C), and the SENDAI-4 for preparedness, recovery and response actions.

Our second hypothesis, that local regulatory documents would be partly correlated with both academic literature and newspapers, was also only partially supported. Some keywords from the SENDAI framework occur most frequently in newspapers, least frequently in the academic literature, and at intermediate frequency in regulatory documents (Figure 4C). This suggests that local regulation places intermediate priority on certain topics, compared to the two other sources of information, in support of its mediation role hypothesized in our second hypothesis. In contrast to this interpretation, however, there is the lack of correlation between UN keyword use in regulatory documents and academic literature (Figure 4), which seem to overlap only for SDG-15.1. Since we only considered local institutional and regulatory documents, this result does not necessarily reflect the focus of national regulatory documents, but points to issues tackled by the local regulatory institutions. Nevertheless, the analysis of local regulation documents shows that the hypothesized intermediate role of regulatory documents is only partial. Thus, regulation does not seem to be significantly connected to the academic literature.

A main finding is that the UN keywords used in the academic literature are not aligned with those used in the newspapers and regulatory documents (as shown by the lack of correlation). European Union funding, focused on the EU Water Framework Directive, might have directed academic research and literature toward biodiversity topics as a priority. Such research and research-funding specificity may have fostered the disconnection from other knowledge advancement needed for more general sustainability governance and policies toward the 2030 Agenda. Indeed, the role of SDGs to foster an ecosystembased disaster risk reduction have already been suggested at global scale (Briceño, 2015) and specifically for Europe (Faivre 
et al., 2018). Furthermore, Tang and Rundblad (2017) showed that the analysis of media reports from newspaper and web-based media exhibits a wide range of patterns due to the differences in language used to communicate specific risks. Other authors have observed disconnections between science and policy, and pointed out the need to intensify interactions, cooperation and inter-and trans-disciplinary research to bridge this gap (Scolobig and Pelling, 2016). Further work is therefore needed to explore the cause for this disconnection between research and the other information sources.

\section{Tagliamento River Management: A Fragmented Debate?}

River management includes a duality in the river representing a resource but, at the same time, also a threat to safety. River managers and policy-makers have often considered rivers as a source of natural hazards while underplaying the role healthy ecosystems have in providing multiple social and economic benefits (Tickner et al., 2017). In our specific case study, the flood risk in the floodplain downstream of the Tagliamento River's braided course represents a major territorial planning issue (Spaliviero, 2003). This issue requires governance strategies that integrate the different branches of society involved in river management, with the general aim of sustainable long-term solutions (Gregory et al., 2011; Di Baldassarre et al., 2018). However, our results show that academic literature, newspapers and regulatory documents focus on different aspects of river management and correlations become evident only when UN keywords are considered (Is There a Disconnection Between Science and Policy?). In the general word occurrence analysis, the most recurrent words in newspapers focus on local management and political aspects, e.g., Latisana, the flood-prone town in the lower course of the river, which is often mentioned. However, the general term risk has low occurrence in newspapers, suggesting that specific locations such as Latisana are considered more important for delivering a message of interest to the general public than technical terms such as risk. However, risk is most occurring word in regulatory documents, followed by hazard. In the academic literature, hazard is number 10 and risk number 12, with the 9 most used words largely relating to conservation, restoration and biodiversity (See General word occurrence and SI). In 2019, a polemic newspaper discussion on water retention basins - which could lower flood risk-was exacerbated by a particularly rainy autumn season. The debate in local newspapers was then mostly conducted by political representatives of different local communities, who presented divergent opinions from "upstream" and "downstream" municipalities on proposed river management actions. The administrative fragmentation and the large divide between the involved stakeholders seem to obstruct consensual decision-making to reduce flood risk in the basin.

While a clear risk-reduction strategy is needed, only a small fraction of academic research on the Tagliamento river is devoted to the estimation of expected flood-related losses and damages.
The word flood is one of the few that occur across the three information sources in the general word occurrence analysis with similar relevance (General Word Occurrence). However, flood is not among the UN keywords, where the more general term risk is used instead. More risk-related research and monitoring may fill important knowledge gaps and support evidence-based knowledge to policy makers and, eventually, the public. For example, river stage is measured continuously in a few crosssections but updated discharge measurements are lacking (Peressi, personal communication). Therefore, the academic literature appears to focus on different aspects of sustainable river management compared to regulatory documents and newspapers - the latter in particular track short-term, urgent issues rather than long-term ones as would be required for sustainable management.

\section{Methodological Implications}

The choices of SDGs and targets, and the keyword selection process are central in our analysis. The targets address widely different water quantity and quality aspects, impacts and risks, and the choices of different UN keywords reflect author subjectivities and may introduce analysis and result biases. Generally defined as value judgment, this concept can play an important role in regulatory science (Elliott, 2019). In this research, subjectivity issues are particularly relevant in the steps involving the choice of UN keywords. In order to prevent problems arising from subjectivity in the choice of water-related SDGs and targets in this study, we performed a two-step selection: each author first independently selected both targets and keywords, and then the choices were compared to identify keywords and related targets selected by all authors, and those chosen by at least one author (Figures 5A,B respectively). The comparison shows only small discrepancies for objectives SDG-12 and SDG-13, while the overall selection pattern is similar, with the highest keyword occurrences exhibited for the SENDAI framework. This means that, in this research, the inclusion of single preferences does not significantly affect the results.

In addition, the fact that we performed an analysis based on two languages may introduce noise. In particular, even if official and technical keywords can be translated based on official documents, the analysis of newspapers requires the use of synonyms to account for the less-technical language typical of the Italian press. In particular, newspapers are likely using the word risk to address a wide range of concerns raised by scholars, as the word can be used as a general term. In this example, though, the word risk does not occur much across newspapers (Tagliamento River Management: A Fragmented Debate?).

The analysis presented here did not explicitly account for the context from which we extracted the words. This decontextualization has been partially overcome through manual screening of newspaper articles, making sure that their content was pertinent to the topic. Moreover, the results are influenced by the language styles of different information sources. To address both of these potential issues, we focus on words that have unique meanings in all the languages involved and/or are less prone to misinterpretation (for instance by focusing on hazard instead of risk when comparing occurrences). Moreover, our approach 
A Occurrence of UN keywords Identified by all 5 authors
B Occurrence of UN keywords

Identified by at least 1 author

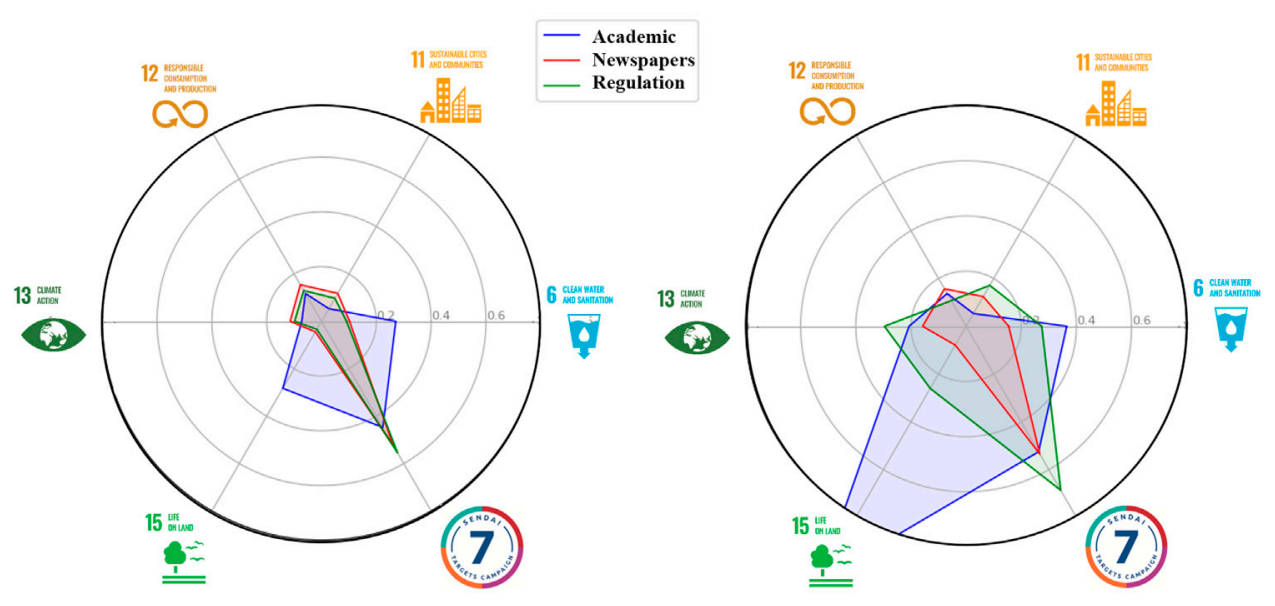

C Filtered vs non-filtered newspapers

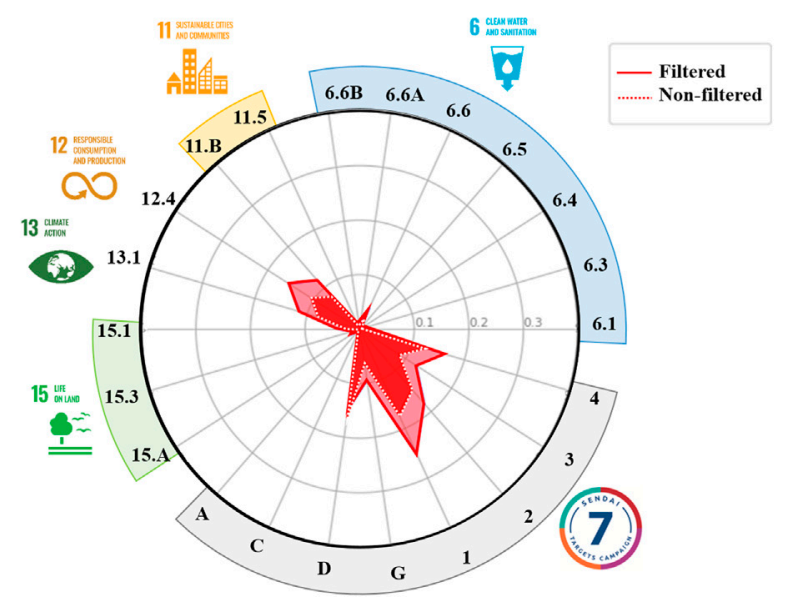

FIGURE 5 | Polar charts showing UN keywords identified across the academic (blue), newspaper (red) and local regulatory (green) document sources from UN objectives considered relevant (A) by all five authors and (B) by at least one author. (C) Occurrences of UN keywords in filtered (solid line) and non-filtered (dashed line) newspaper articles normalized by the total number of words in filtered and non-filtered newspapers (note that the number of words in the unfiltered newspapers is about three times the number of words of the filtered newspapers).

combines automated and manual screening of content, as advocated by Hamborg et al. (2019), providing a simple yet flexible methodology.

Across the information sources, there is a temporal mismatch with newspapers covering the last 20 years, and scientific articles covering a longer period, starting in the 1990s. Lengthening the search period increased the number of research articles only somewhat-a total of 8 publications between 1993 and 2000, out of 238 retained research articles. However, removing the earlier research articles does not affect the results (not shown). Additionally, we controlled for differences in the length and number of documents by normalizing the UN keywords by the total number of words in each information source (Figure 4A) this allows comparing keyword occurrences across targets for each information source.
Our methodology is based on the analysis of text documents and can be improved with more sophisticated tools for article retrieval and text analysis. Regulation documents were available in pdf format, and the conversion to text may lead to errors (e.g., encoding). As for the academic articles, authors-defined and automatically retrieved keywords cover different topics, but their efficacy in summarizing a scientific contribution still needs to be explored (Zhang et al., 2016). The scraping of online content from newspaper sites is conditioned by (i) the newspaper's search engine, (ii) the server response, which may be temporarily unavailable, and (iii) the html structure that may change in time. These limitations may be solved by using digital archives or Application Programming Interfaces (APIs) on web content using existing content tags when available (Afonso et al. 2012). In addition, the scraped newspaper articles were filtered 
manually in order to discard items that were not significant for the analysis. This is a necessary step because the scraping script is not able to detect aspects such as the appropriateness of the topic. However, it also introduces some subjectivity in the methodology. To assess the impact of this subjective step, we also compared results before and after the manual filtering. The analysis of UN keywords occurrences normalized by number of words in each source shows that the normalized occurrences in filtered articles are higher than in the total (non-filtered) articles (Figure 5C). This is due to the fact that the filtered articles deal with pertinent topics, so that the likelihood of finding UN keywords is higher, even though the number of words in the non-filtered newspaper articles is approximately three times the number of words in the filtered articles. In contrast, the non-filtered articles contain also non-relevant content, which is unlikely to contain the UN keywords, indicating that discarding the articles did not affect the final result (Figure 5C). Thus, the methodology is robust with respect to the manual filtering step.

Some differences appear when analyzing relevance for SDG-6 and SDG-11. The associated SDGs keywords occurred more frequently in the unfiltered newspaper articles, in particular due to many articles related to drinking water quality. Some of these articles were discarded through manual filtering because the water source was not the Tagliamento River but other rivers and lakes in the region. The articles related to the following human activities, but not directly related to the Tagliamento River, were also discarded:

- highway construction work,

- deaths/incidents to people,

- advertisement to various events that "use" the river but not directly related to their impacts

- drinking water issues (not related to the river stream but to alpine dams)

In addition, the manual filtering of newspaper articles allowed the authors to identify a list of hot topics that underline the importance of interactions between society and the river system, and in particular impacts and losses associated with extreme river events. The following hot topics were identified and retained:

- waste dumped into the river

- river drought and impact on agriculture

- river floods

- maintenance of river levee/banks

- river access (e.g., bike and car races) and its impacts on the environment

The hot topics identified in manual filtering and the discarded activities show aspects of relevance to society that affect politics and governance in the area. Such topics also need to be addressed by the scientific community in order to a) improve the evidence basis for socio-political debate, and b) give better tools to address and solve the issues (as mentioned by Goodall, 2008).

Communicating natural hazards and risk is a complex task, involving aspects ranging from cultural factors to personal experiences and beliefs (Terpstra et al., 2009; Wachinger et al.,
2013). Feldman et al. (2016) show that both traditional and social media play an important role in disseminating risk-related information to the public. Some media-driven initiatives have already been effective in increasing public attention on the value of the Tagliamento River: the movie entitled 'White Noise' (Fasulo, 2008), which depicted the natural forces shaping the river and the relationship between local communities and the river; and the national television show 'Sapiens' (Tozzi, 2019), which dedicated an episode to the Tagliamento River, underlying its uniqueness in Europe and the need to preserve it. However, social media can also contribute to debate polarization and spreading of fake news and false information (Lazer et al., 2018). These aspects require further analyses of a wide spectra of sources such as newspapers, social media (e.g., Twitter) television, cinema, etc. In particular, social media analyses can provide meaningful information on societal risk perception and serve as powerful tools during emergency situations such as floods.

Preliminary analysis of Twitter content, scraped via a Python script, shows that in the period 2008-2020 there are a total 1,110 and 592 tweets for the search key 'fiume Tagliamento' and 'Tagliamento river', respectively (search performed in March 2020). Given that most tweets are concentrated over the last five years (2015-2019), and the tweet content is too small to perform a robust occurrence analysis, they were not included in the present work. As for Facebook and other social media, feasibility and legal limitations of the scraping process should be assessed, and might be replaced by the use of specific APIs. Finally, the analysis of social aspects can be complemented with surveys and questionnaires, e.g., on water-related hazards. All these different sources of information may be considered in the methodology presented here, to achieve a better understanding of the different sector priorities, perceptions, and their relationships with the 2030 Agenda and its challenges.

\section{Future Outlook}

Although both public and academic attention for river-floodplain systems management have been increasing in the last decades, there is intense debate on the utility of scientific results for decision-making purposes (Dilling and Lemos, 2011). Scientific findings and integrated river management strategies need to be effectively communicated between both sectors as well as with the general public (Baan and Klijn, 2010). Scientists need to become facilitators in these societal interaction processes (Köhler et al., 2019; Schneider et al., 2019; Turnheim et al., 2020). For example, results from socio-hydrological studies could assist communities to make informed decisions that account for management of water resources and other aspects of sustainable development (Bai et al., 2016; Di Baldassarre et al., 2019). However, this study shows that the topics covered by academia, regulatory bodies and newspapers are rather disconnected, as observed elsewhere (Liu et al., 2008; Weichselgartner and Kasperson, 2010). For policymakers to integrate scientific findings, a common vocabulary is necessary.

To meet the sustainability objectives within the 2030 Agenda, participatory research approaches are needed, but remain poorly 
integrated into the larger-scale assessments that dominate the SDG research (Bennich et al., 2020). Participatory approaches could include surveyed perception on water-related hazards (See 4.3), or hot topics identified here, to move discussion toward a concerted view on the future of river management that could take into account both river protection and risk management. Furthermore, standardization of terminology and time-frame perspectives are necessary to communicate across stakeholder groups. While sustainability typically relates to long-term processes, various intermediaries (e.g., newspapers and their audience) may focus on short-term time scales. Agreement in terminology and applicable time-scale is necessary for research to be shared with relevant stakeholders at local, regional and global levels, as also suggested by the Responsible Research and Innovation guidelines (European Commission, 2020). Participatory approaches increase interaction across sectors and help to develop uniform terminology. This in turn can enhance the co-creation of knowledge and social learning, spread common understanding of concepts, as well as augment collaborative approaches between researchers and other societal actors (Estellie Smith, 1995; Bruckmeier and Höj Larsen, 2008; Leys and Vanclay, 2011; Page et al., 2020). Continued and expanded use of the methodology developed and presented in this study can help quantify the effects of such joint efforts to progressively improve communication and knowledge transfer across the science-policy-practice interface.

\section{CONCLUSION}

We have assessed differences among academic, newspaper and local regulatory information sources on river-related UN sustainability objectives in the 2030 Agenda by analyzing: (i) general word occurrences in the information sources, and (ii) occurrences of specific UN keywords associated with the SDG and SENDAI frameworks. Across the three information sources, we observe the greatest disconnection between the academic and local regulatory sources, whereas topics covered by newspapers are partially correlated with those covered in either academic or regulatory documents.

The SDG and SENDAI objectives provide a framework for political and local stakeholders to design effective river management strategies and practices. In turn, these strategies and practices rely on continuous progress made by scientific research. These research activities should be communicated with and informed by the needs and knowledge of society

\section{REFERENCES}

Afonso, L. M., Cerqueira, R. F. de. G., and de Souza, C. S. (2012). "Evaluating application programming interfaces as communication artefacts," in Proceedings of the psychology of programming interest group Annual conference 2012 (PPIG'2012). London, UK: The Psychology of Programming Interest Group, 151-162. and the public. While sustainability issues are covered consistently in newspapers and regulatory documents, the discrepancies between scientific literature and regulatory documents indicate that there are only limited two-way interactions between science and policy.

\section{DATA AVAILABILITY STATEMENT}

The original contributions presented in the study are included in the article Supplementary Material, further inquiries can be directed to the corresponding author.

\section{AUTHOR CONTRIBUTIONS}

AS: Conceptualization, Data curation, Methodology development, Visualization, Writing- Original draft preparation. CS: Conceptualization, Data curation, Methodology development, Visualization, Writing - reviewing and editing. JF: Methodology validation, Writing - reviewing and editing. GD: Methodology validation, Writing - reviewing and editing. SM: Conceptualization, Writing - reviewing and editing.

\section{FUNDING}

SM, AS and GD acknowledge support from the Swedish Research Agencies (SM, AS: Vetenskapsrådet/Formas/Sida 2016-06313 and Formas 2018-02321; GD: Formas 2016-02045), and the Bolin Center for Climate Research (RA7). CS acknowledges support from OGS (National Institute of Oceanography and Applied Geophysics), Italy.

\section{ACKNOWLEDGMENTS}

We thank Gabriele Peressi from the Friuli Venezia-Giulia Civil Protection for his useful suggestions, and two reviewers for their constructive criticism.

\section{SUPPLEMENTARY MATERIAL}

The Supplementary Material for this article can be found online at: https://www.frontiersin.org/articles/10.3389/fenvs.2021.553822/ full\#supplementary-material.

Albert, J. S., Destouni, G., Duke-Sylvester, S. M., Magurran, A. E., Oberdorff, T., Reis, R. E., et al. (Forthcoming 2020). Scientists' warning to humanity on the freshwater biodiversity crisis. Ambio 50, 85-94. 10.1007/s13280-020-01318-8.

Audipress (2017). Visual report-lettori quotidiani per provincia. Available at: dipress.it/visual_report/m/2017_I/cartarep (Accessed 2017).

Baan, P. J. A., and Klijn, F. (2010). Flood risk perception and implications for flood risk management in The Netherlands. Int. J. River Basin Manag. 2, 113-122. doi:10.1080/15715124.2004.9635226 
Bacini Idrografici delle Alpi Orientali (2009). Sintesi delle pressioni e degli impatti significativi esercitati dalle attività umane sullo stato delle acque superficiali e sotterranee. Available at: https://www.adbpo.it/PianoAcque2015/Elaborato_ 02_PressioniImpatti_3mar16/PdGPo2015_Elab_2_PressioniImpatti_3mar16. pdf (Accessed 2009).

Bai, X., van der Leeuw, S., O’Brien, K., Berkhout, F., Biermann, F., Brondizio, E. S., et al. (2016). Plausible and desirable futures in the Anthropocene: a new research agenda. Global Environ. Change 39, 351-362. doi:10.1016/j. gloenvcha.2015.09.017

Batista, P. V. G., Davies, J., Silva, M. L. N., and Quinton, J. N. (2019). On the evaluation of soil erosion models: are we doing enough? Earth Sci. Rev. 197, 102898. doi:10.1016/j.earscirev.2019.102898

Bennich, T., Weitz, N., and Carlsen, H. (2020). Deciphering the scientific literature on SDG interactions: a review and reading guide. Sci. Total Environ. 728, 138405. doi:10.1016/j.scitotenv.2020.138405

Borrely, S. I., Rosa, J. M., Boiani, N. F., Garcia, V. S. G., and Sousa, A. L. (2018). Emerging pollutants, related toxicity, and water quality decreasing: tannery, textile, and pharmaceuticals load pollutants. Biol. Eng. Med. 3, 1-6. doi:10. 15761/BEM.1000157

Bouwman, A. F., Beusen, A. H. W., and Billen, G. (2009). Human alteration of the global nitrogen and phosphorus soil balances for the period 1970-2050. Global Biogeochem. Cycles 23, a-n. doi:10.1029/2009GB003576

Bowles, T. M., Atallah, S. S., Campbell, E. E., Gaudin, A. C. M., Wieder, W. R., and Grandy, A. S. (2018). Addressing agricultural nitrogen losses in a changing climate. Nat Sustain 1, 399-408. doi:10.1038/s41893-018-0106-0

Briceño, S. (2015). Looking back and beyond Sendai: 25 Years of international policy experience on disaster risk reduction. Int J Disaster Risk Sci 6, 1-7. doi:10. 1007/s13753-015-0040-y

Bruckmeier, K., and Höj Larsen, C. (2008). Swedish coastal fisheries-From conflict mitigation to participatory management. Mar. Pol. 32, 201-211. doi:10.1016/j. marpol.2007.09.005

Brusarosco, A., Rossato, S., and Ziliani, L. (2010). Conflitti d' acqua e di uomini nel bacino del Tagliamento: l'utilità di un approccio integrato tra geografia umana e fisica. Quad del dottorato 4, 193-212.

Carabine, E. (2015). Revitalising evidence-based policy for the Sendai Framework for disaster risk reduction 2015-2030: lessons from existing international science partnerships. PLoS Curr. 7, 1-18. doi:10.1371/currents.dis. aaab45b2b4106307ae2168a485e03b8a

Damania, R., Rodella, A., Russ, J., and Zaveri, E. (2019). Quality unknown. Washington, DC: International Bank for Reconstruction and Development/ The World Bank.

Destouni, G., Fischer, I., and Prieto, C. (2017). Water quality and ecosystem management: data-driven reality check of effects in streams and lakes. Water Resour. Res. 53, 6395-6406. doi:10.1002/2016WR019954

Destouni, G., and Verrot, L. (2014). Screening long-term variability and change of soil moisture in a changing climate. J. Hydrol. 516, 131-139. doi:10.1016/j. jhydrol.2014.01.059

Di Baldassarre, G., Sivapalan, M., Rusca, M., Cudennec, C., Garcia, M., Kreibich, H., et al. (2019). Sociohydrology: scientific challenges in addressing the sustainable development goals. Water Resour. Res. 55, 6327-6355. doi:10.1029/ 2018WR023901

Di Baldassarre, G., Kreibich, H., Vorogushyn, S., Aerts, J., Arnbjerg-Nielsen, K., Barendrecht, M., et al. (2018). Hess opinions: an interdisciplinary research agenda to explore the unintended consequences of structural flood protection. Hydrol. Earth Syst. Sci. 22, 5629-5637. doi:10.5194/hess-225629-2018

Di Baldassarre, G., Viglione, A., Carr, G., Kuil, L., Salinas, J. L., and Blöschl, G. (2013). Socio-hydrology: conceptualising human-flood interactions. Hydrol. Earth Syst. Sci. 17, 3295-3303. doi:10.5194/hess-17-3295-2013

Dilling, L., and Lemos, M. C. (2011). Creating usable science: opportunities and constraints for climate knowledge use and their implications for science policy. Global Environ. Change 21, 680-689. doi:10.1016/j.gloenvcha.2010.11.006

Elliott, K. C. (2019). Managing value-laden judgements in regulatory science and risk assessment. EFSA J 17, e170709-e170711. doi:10.2903/j.efsa.2019.e170709

Elmhagen, B., Destouni, G., Angerbjörn, A., Borgström, S., Boyd, E., Cousins, S. A. O., et al. (2015). Interacting effects of change in climate, human population, land use, and water use on biodiversity and ecosystem services. E\&S 20, 23. doi:10.5751/ES-07145-200123
Engström, R., Destouni, G., Howells, M., Ramaswamy, V., Rogner, H., and Bazilian, M. (2019). Cross-scale water and land impacts of local climate and energy policy-A local Swedish analysis of selected SDG interactions. Sustainability 11, 1847-1928. doi:10.3390/su11071847

Estellie Smith, M. (1995). The nature of Nature: conflict and consensus in fisheries management. Aquat. Living Resour. 8, 209-213. doi:10.1051/alr:1995020

European Commission (2008). Groundwater protection in Europe - the new groundwater directive-consolidating the EU regulatory framework. Luxembourg: Office for Official Publications of the European Communities.

European Commission (2020). "Science with and for society," in Horizon 2020-work programme 2018-2020.

European Council (2000). Directive 2000/60/EC of the European Parliament and of the Council of 23 October 2000 establishing a framework for Community action in the field of water policy. Available at: https://eur-lex.europa.eu/eli/dir/ 2000/60/oj (Accessed October 23, 2000).

European Environment Agency (2019). Economic losses from climate-related extremes in Europe. Available at: https://www.eea.europa.eu/data-and-maps/ indicators/direct-losses-from-weather-disasters-3/assessment-2 (Accessed 2019).

Faivre, N., Sgobbi, A., Happaerts, S., Raynal, J., and Schmidt, L. (2018). Translating the Sendai Framework into action: the EU approach to ecosystem-based disaster risk reduction. Int. J. Disaster Risk Reduct. 32, 4-10. doi:10.1016/j. ijdrr.2017.12.015

Fasulo, A. (2008). Rumore bianco. Italy, Switzerland.

Feldman, D., Contreras, S., Karlin, B., Basolo, V., Matthew, R., Sanders, B., et al. (2016). Communicating flood risk: looking back and forward at traditional and social media outlets. Int. J. Disaster Risk Reduct. 15, 43-51. doi:10.1016/j.ijdrr. 2015.12.004

Feldpausch-Parker, A. M., Ragland, C. J., Melnick, L. L., Chaudhry, R., Hall, D. M., Peterson, T. R., et al. (2013). Spreading the news on carbon capture and storage: a state-level comparison of US media. Environ. Commun. 7, 336-354. doi:10. 1080/17524032.2013.807859

Fukuda-Parr, S. (2016). From the millennium development goals to the sustainable development goals: shifts in purpose, concept, and politics of global goal setting for development. Gend. Dev. 24, 43-52. doi:10.1080/13552074.2016.1145895

Garfield, E., and Sher, I. H. (1993). Keyword plus-algorythm derivative indexing. J. Am. Soc. Inf. Sci. 44, 298-299. 10.1002/(SICI)1097-4571(199306)44:5\% 3C298::AID-ASI5\%3E3.0.CO;2-A.

Goodall, A. H. (2008). Why have the leading journals in management (and other social sciences) failed to respond to climate change? J. Manag. Inq. 17, 408-420. doi:10.1177/1056492607311930

Gregory, C., Brierley, G., and Le Heron, R. (2011). Governance spaces for sustainable river management. Geogr Compass 5, 182-199. doi:10.1111/j. 1749-8198.2011.00411.x

Grill, G., Lehner, B., Thieme, M., Geenen, B., Tickner, D., Antonelli, F., et al. (2019). Mapping the world's free-flowing rivers. Nature 569, 215-221. doi:10.1038/ s41586-019-1111-9

Hale, B. W. (2010). Using newspaper coverage analysis to evaluate public perception of management in river-floodplain systems. Environ. Manag. 45, 1155-1163. doi:10.1007/s00267-010-9456-8

Hamborg, F., Donnay, K., and Gipp, B. (2019). Automated identification of media bias in news articles: an interdisciplinary literature review. Int. J. Digit. Libr. 20, 391-415. doi:10.1007/s00799-018-0261-y

Howarth, R., Swaney, D., Billen, G., Garnier, J., Hong, B., Humborg, C., et al. (2012). Nitrogen fluxes from the landscape are controlled by net anthropogenic nitrogen inputs and by climate. Front. Ecol. Environ. 10, 37-43. doi:10.1890/100178

IPCC (2012). National systems for managing the risks from climate extremes and disasters. Cambridge: Cambridge University Press.

Jaramillo, F., Desormeaux, A., Hedlund, J., Jawitz, J., Clerici, N., Piemontese, L., et al. (2019). Priorities and interactions of sustainable development goals (SDGs) with focus on wetlands. Water 11, 619-621. doi:10.3390/w11030619

Kennamer, J. D. (1992). "Public opinion, the press, and public policy: an introduction," in Public opinion, the press, and public policy. Editor J. D. Kennamer (Westport, CT: Praeger Publishers), 1-18.

Köhler, J., Geels, F. W., Kern, F., Markard, J., Onsongo, E., Wieczorek, A., et al. (2019). An agenda for sustainability transitions research: state of the art and future directions. Environ. Innov. Soc. Transit. 31, 1-32. doi:10.1016/j.eist.2019. 01.004 
Lazer, D. M. J., Baum, M. A., Benkler, Y., Berinsky, A. J., Greenhill, K. M., Menczer, F., et al. (2018). The science of fake news. Policy Froum 359, 1094-1096. doi:10. $1126 /$ science.aao2998

Le Blanc, D. (2015). Towards integration at last? The sustainable development goals as a network of targets. New York. Available at: https://www.un.org/ development/desa/publications/working-paper/towards-integration-at-last (Accessed March 1, 2015).

Leys, A. J., and Vanclay, J. K. (2011). Stakeholder engagement in social learning to resolve controversies over land-use change to plantation forestry. Reg. Environ. Change 11, 175-190. doi:10.1007/s10113-010-0132-6

Ligtvoet, W. (2018). The geography of future water challenges. The Hague: PBL Netherlands Environmental Assessment Agency.

Liu, Y., Gupta, H., Springer, E., and Wagener, T. (2008). Linking science with environmental decision making: experiences from an integrated modeling approach to supporting sustainable water resources management. Environ. Model. Software 23, 846-858. doi:10.1016/j.envsoft.2007.10.007

Ma, P., Wei Wang, m., Liu, H., Feng Chen, y., and Xia, J. (2019). Research on ecotoxicology of microplastics on freshwater aquatic organisms. Environ. Pollut. Bioavailability 31, 131-137. doi:10.1080/26395940.2019.1580151

Mora-Valentín, E.-M., Ortiz-de-Urbina-Criado, M., and Nájera-Sánchez, J.-J. (2018). Mapping the conceptual structure of science and technology parks. J. Technol. Tran. 43, 1410-1435. doi:10.1007/s10961-018-9654-8

Muller, M. E. (1956). Some continuous Monte Carlo methods for the dirichlet problem. Ann. Math. Stat. 27, 569-589. doi:10.1214/aoms/1177728169

Muller, N. (1995). River dynamics and floodplain vegetation and their alterations due to human impact. Arch. Hydrobiol. Suppl. 101, 477-512.

Nilsson, M., Chisholm, E., Griggs, D., Howden-Chapman, P., McCollum, D., Messerli, P., et al. (2018). Mapping interactions between the sustainable development goals: lessons learned and ways forward. Sustain. Sci. 13, 1489-1503. doi:10.1007/s11625-018-0604-z

Nilsson, M., Griggs, D., and Visbeck, M. (2016). Policy: map the interactions between sustainable development goals. Nature 534, 320-322. doi:10.1038/ 534320a

Oliveira, C., and Almeida, S. (2019). A systemic and contextual framework to define a country's 2030 agenda from a foresight perspective. Sustainability 11, 6360. doi:10.3390/su11226360

Page, J., Mörtberg, U., Destouni, G., Ferreira, C., Näsström, H., and Kalantari, Z. (2020). Open-source planning support system for sustainable regional planning: a case study of Stockholm County, Sweden. Environ. Plan. B Urban Anal. City Sci. 47, 1508-1523. doi:10.1177/2399808320919769

Paronuzzi, P. (2005). "Le acque," in Il Tagliamento. Editors F. Bianco, A. Bondesan, P. Paronuzzi, and M. Z. A. Zanetti (Sommacampagna, VR: CIERRE Edizioni), 165-207.

Patenaude, G. (2011). Climate change diffusion: while the world tips, business schools lag. Global Environ. Change 21, 259-271. doi:10.1016/j.gloenvcha.2010. 07.010

Riffe, D., Lacy, S., Fico, F., and Watson, B. (2019). Analyzing media messages using quantitative content analysis in research, fourth. New York: Routledge Communication Series.

Santos, C. E. M., and Nardocci, A. C. (2019). Prioritization of pharmaceuticals in drinking water exposure based on toxicity and environmental fate assessment by in silico tools: an integrated and transparent ranking. Comput Toxicol 9 , 12-21. doi:10.1016/j.comtox.2018.10.005

Schneider, F., Kläy, A., Zimmermann, A. B., Buser, T., Ingalls, M., and Messerli, P. (2019). How can science support the 2030 Agenda for Sustainable Development? Four tasks to tackle the normative dimension of sustainability. Sustain Sci 14, 1593-1604. doi:10.1007/s11625-019-00675-y

Scolobig, A., and Pelling, M. (2016). The co-production of risk from a natural hazards perspective: science and policy interaction for landslide risk management in Italy. Nat. Hazards 81, 7-25. doi:10.1007/s11069-015-1702-1

Spaliviero, M. (2003). Historic fluvial development of the Alpine-foreland Tagliamento River, Italy, and consequences for floodplain management. Geomorphology 52, 317-333. doi:10.1016/S0169-555X(02)00264-7
Tang, C., and Rundblad, G. (2017). When safe means "dangerous": a corpus investigation of risk communication in the media. Appl. Linguist. 38, 666-687. doi:10.1093/applin/amv058

Terpstra, T., Lindell, M. K., and Gutteling, J. M. (2009). Does communicating (flood) risk affect (flood) risk perceptions? results of a quasi-experimental study. Risk Anal. 29, 1141-1155. doi:10.1111/j.1539-6924.2009.01252.x

Tickner, D., Parker, H., Moncrieff, C. R., Oates, N. E. M., Ludi, E., and Acreman, M. (2017). Managing rivers for multiple benefits-A coherent approach to research, policy and planning. Front. Environ. Sci. 5, 1-8. doi:10.3389/fenvs.2017.00004

Tockner, K., Ward, J. V., Arscott, D. B., Edwards, P. J., Kollmann, J., Gurnell, A. M., et al. (2003). The Tagliamento River: a model ecosystem of European importance. Aquat. Sci. 65, 239-253. doi:10.1007/s00027-003-0699-9

Toniutti, N. (2004). "Integrazione," in Studio preliminare per l'individuazione di alternative alle casse di espansione previste nel medio corso del fume Tagliamento. Vol. 2.

Toniutti, N., and Ludovici, A. A. (2002). Tagliamento fiume d'Europa-il problema delle casse di espansione. Rome.

Toniutti, N. (2003). Aspetti idraulici, socio-economici e ambientali," in Studio preliminare per l'individuazione di alternative alle casse di espansione previste nel medio corso del fiume Tagliamento. Vol. I.

Tozzi, M. (2019). Sapiens - un solo pianeta.

Turnheim, B., Asquith, M., and Geels, F. W. (2020). Making sustainability transitions research policy-relevant: challenges at the science-policy interface. Environmental Innovation and Societal Transitions 34, 116-120. doi:10.1016/j.eist.2019.12.009

United Nations (2015b). Quadro di Riferimento di Sendai per la Riduzione del Rischio di Disastri 2015-2030. 1-26.

United Nations (2015a). Transforming our world: the 2030 Agenda for Sustainable Development, outcome document of the United Nations summit for the adoption of the post-2015 agenda, RES/A/70/L.1. Resolut. Adopt. Gen. Assem. Available at: https://www.un.org/en/development/desa/population/ migration/generalassembly/docs/globalcompact/A_RES_70_1_E.pdf (Accessed October 21, 2015).

Wachinger, G., Renn, O., Begg, C., and Kuhlicke, C. (2013). The risk perception paradox--implications for governance and communication of natural hazards. Risk Anal. 33, 1049-1065. doi:10.1111/j.1539-6924.2012.01942.x

Ward, J. V., Tockner, K., Edwards, P. J., Kollmann, J., Bretschko, G., Gurnell, A. M., et al. (1999). A reference river system for the Alps: the "Fiume Tagliamento". Regul. Rivers Res. Manag. 15, 63-75. doi:10.1002/(SICI)1099-1646(199901/06) 15:1/3<63::AID-RRR538>3.0.CO;2-F

Weichselgartner, J., and Kasperson, R. (2010). Barriers in the science-policypractice interface: toward a knowledge-action-system in global environmental change research. Global Environ. Change 20, 266-277. doi:10. 1016/j.gloenvcha.2009.11.006

Woodward, J. L. (1934). Quantitative newspaper analysis as a technique of opinion research. Soc. Forces 12, 526-537. doi:10.2307/2569712

Zhang, J., Yu, Q., Zheng, F., Long, C., Lu, Z., and Duan, Z. (2016). Comparing keywords plus of WOS and author keywords: a case study of patient adherence research. J Assn Inf Sci Tec 67, 967-972. doi:10.1002/asi.23437

Conflict of Interest: Author JF was employed by the company Ramboll.

The remaining authors declare that the research was conducted in the absence of any commercial or financial relationships that could be construed as a potential conflict of interest.

Copyright $\odot 2021$ Scaini, Scaini, Frentress, Destouni and Manzoni. This is an openaccess article distributed under the terms of the Creative Commons Attribution License (CC BY). The use, distribution or reproduction in other forums is permitted, provided the original author(s) and the copyright owner(s) are credited and that the original publication in this journal is cited, in accordance with accepted academic practice. No use, distribution or reproduction is permitted which does not comply with these terms. 